\title{
Fabrication and Characterization of Nano Titania-Magnetic Reduced Graphene Oxide with Highly Photocatalytic Degradation of Tartrazine Dye
}

\author{
M. S. Elmowafy ${ }^{*}$, Amr .A. Nada ${ }^{\dagger}$, H.R.Tantawy ${ }^{\ddagger}$ and M.A.Elsayed ${ }^{\S}$
}

\begin{abstract}
In this paper, magnetic nanocomposites are synthesized by loading reduced graphene oxide $(\mathrm{RG})$ with two components of nanoparticles consisting of titanium dioxide $\left(\mathrm{TiO}_{2}\right)$ and magnetite $\left(\mathrm{Fe}_{3} \mathrm{O}_{4}\right)$ with varying amounts. The resulting $\mathrm{TiO}_{2} /$ magnetite reduced graphene oxide (MRGT) composite demonstrate intrinsic visible light photocatalytic activity, on degradation of tartrazine (TZ) dye from a synthetic aqueous solution. Specifically, it exhibits higher photoactivity than magnetite reduced graphene oxide (MRG) and TiO2 nanoparticles. The photocatalytic degradation of (TZ) by MRGT composites under visible light irradiation was examined by varying the operational parameters such as photocatalyst amounts, organic dye concentrations, and irradiation time. The structural and magnetic features of the prepared composite photocatalysts were investigated by powder X-ray diffraction (XRD), Fourier transform infrared spectra (FT-IR), transmission electron microscopy (TEM), UV-vis diffuse reflectance spectra (UV-vis/DRS) -, Raman and vibrating sample magnetometer (VSM). The photocatalytic degradation of TZ dye when using MRG and $\mathrm{TiO}_{2}$ for $3 \mathrm{~h}$ under visible light was $35 \%$ and $10 \%$ respectively, Whereas for MRGT it was more than $95 \%$. The higher photocatalytic efficiency of MRGT is due to the existence of reduced graphene oxide and magnetite which enhance the photocatalytic effienecy of the composite in visible light.
\end{abstract}

Keywords: Reduced Graphene oxide, Tartrazine, Titanium dioxide, Photocatalyst, GO, Magnetite.

\section{Introduction}

Water contamination has become one of the dominant problems in everyday life. Increasing the manufacturing wastewater from materials, foods, medicines, etc. which containing various kinds of dyes such as make it more worrying[1].

Strongly colored effluents can make environmental problems, in addition to influence, the human life as the greater part of them are cancer-causing and mutagenic[2]. The reports demonstrate that it is approximately $10-15 \%$ of the dyes is missed in the effluent during dyeing procedure[3].

Egyptian Armed Forces, Egypt; mowafy41@yahoo.com

Egyptian Petroleum Research Institute, 11727, Cairo, Egypt; Institut Européen des Membranes, Université Montpellier 2, CC 047, Place Eugène Bataillon, 34095, Montpellier Cedex 5, France.

Egyptian Armed Forces, Egypt.

Egyptian Armed Forces, Egypt. 
These dyes are considered as nonoxidizable by traditional physical and biological remediation because of the complex of their molecular structure and their large size molecules. So, their decolorization is considered as an essential procedures in wastewater treatment[4].

One of these dyes is tartrazine dye, which is a water soluble acidic azo dye (FD \& C Yellow No. 5, EEC Number $=$ E102, CI Number $=19140)$ which has the following chemical structure [trisodium 5-hydroxy-1-(4-sulfonatophenyl)- 4-(4 sulfonatophenylazo)-H-pyrazol-3carboxylate $][5,6]$.

Tartrazine dye is a water-soluble powder which is greatly used in nutrition products, medicines, and cosmetics[7-9]. The suitable dose per person is $0-7.5 \mathrm{mg} / \mathrm{kg}$ body weight[10]. Tartrazine is considered as a dangeriouse azo dye because it catalyze ADHD syndrome, asthma, migraine and thyroid cancer, and other reactions can include blurred vision, itching, purpura, eczema, mutogenetics, and carcinogenetic [11].

At the present time, due to these problems, it is necessary to develop highly effective and sensitive techniques to remove pollutants from water environment. Various types of techniques were used for this purpose, for example, photocatalytic degradation, hetero catalytic phenton, electrochemical removal, and different kinds of adsorbent such as adsorbents prepared from industrial waste, carbon nanotube composite and natural adsorbents, and bottom ash and de-oiled soya were utilized.

In recent times, heterogeneous photocatalytic oxidation, one of the Advanced Oxidation Processes (AOPs), has involved much attention and has confirmed to be an effective technology for degradation of an organic contaminants at ambient conditions[12]. Its advantage is the complete degradation of organic pollutants compared with the other water purification techniques[13].

In this technique, photogenerated charge carriers in a semiconductor photocatalyst and the creation of extremely reactive chemical species like hydroxyl radicals could mineralize a wide range of organic contaminants rapidly and non-selectively [14].

The most usually utilized photocatalyst is $\mathrm{TiO}_{2}$ which has been utilized as promising photocatalyst for the degradation of organic molecules from wastewater due to its distinguish and distinctive properties like high stability, low toxicity and low cost[15]. However, the photocatalytic efficiency of $\mathrm{TiO}_{2}$ is restricted due to the high recombination rate of electronhole within the $\mathrm{TiO}_{2}$ particles with respect to the time scale of the required redox reaction, and its wide band gap. So, only $4 \%$ to $5 \%$ of the sunlight (UV irradiation) can activate $\mathrm{TiO}_{2}$ at wavelengths smaller than $380 \mathrm{~nm}[16]$.

The method used to overcome the wide band gap of $\mathrm{TiO}_{2}$ is the modification of the electronic band structure of the $\mathrm{TiO}_{2}$ by chemical reaction with a substances which used as a source of charge-carrier traps and increase the lifetime of separated electron-hole pairs. In this study, Reduced Graphene oxide (RG) and Magnetite (M) were used with Titanium dioxide (T) to form MRGT composite[17, 18].

Graphene (RG), a single-atom layer of graphite, has been displayed to own amazing catalytic, electrocatalytic, electrochemical sensing and electrochemical energy conversion properties[19]. This two-dimensional network of carbon with high theoretical specific surface area has an excellent mechanical strength, structural elasticity and chemical stability[20]. It also displays brilliant mobility of charge carriers and noble thermal conductivity. These 
properties make graphene very desirable support for semiconductor and metal nanoparticles[21].

The incorporation of graphene ( $\mathrm{RG})$ into $\mathrm{TiO}_{2}$ may give good advantages as follows:

(a) Increased adsorptivity, where graphene displays a particularly worthy adsorptive property; (b) Extended visible light absorption, in which the chemical bonds of Ti-O-C provide a red shift in the photo-responding range that facilitate an extra efficient utilization of visible light for the catalyst. (c) Inhibit charge recombination [22].

Recently, magnetic separation technology has provided a suitable method for eliminating and recycling magnetic particles/composites by applying suitable magnetic field. $\mathrm{Fe}_{3} \mathrm{O}_{4}(\mathrm{M})$ nanoparticles with a fast and efficient magnetic response can allow the separation of catalysts from reaction mixture with any problem and efficiently. Thus, MRGT composite is needed to be recoverable and an efficient photocatalyst towards contaminant degradation [23].

In this work, the MRGT composite photocatalysts were synthesized by various methods. The photocatalytic activity of the MRGT composite photocatalysts was exploited for the photodegradation of a model organic dye tartrazine (TZ) in a suspension system. The main target of our work is to estimate the potential application of this kind of material in the removal of organic contaminants in water [24].

\section{Experimental}

\subsection{Materials}

Graphite powder 99.5\%, Ferric chloride 99\%, Ammonia solution 30\%, titanium (IV) isopropoxide, and isopropyl alcohol were purchased from Sigma Aldrich. Sodium nitrate 99\%, Potassium permanganate $98 \%$, Sulfuric acid 98\%, Hydrogen peroxide 35\%, Ferrous Sulfate $98 \%$ were obtained from alpha chemicals, Egypt. Commercial industrial tartrazine were acquired from local markets, Egypt. All purchased compounds are used as received, with no further purification.

\subsection{Synthesis of graphene oxide (GO)}

Graphene oxide was synthesized by Hummer method using manufactured graphite powder as a starting material. The GO preparation is described by the following procedures: graphite (5 $\mathrm{g})$, sodium nitrate $\left(\mathrm{NaNO}_{3}, 2.50 \mathrm{~g}\right)$ and concentrated sulfuric acid $\left(\mathrm{H}_{2} \mathrm{SO}_{4}, 115 \mathrm{ml}\right)$ were added into a $2 \mathrm{~L}$ beaker, which is kept at $5{ }^{\circ} \mathrm{C}$ in an ice bath under stirring for $10 \mathrm{~min}$. At that point, potassium permanganate $\left(\mathrm{KMnO}_{4}, 15 \mathrm{~g}\right)$ was gradually added into the beaker to inhibit any severe reaction that might take place. The mixture was kept under stirring at $5{ }^{\circ} \mathrm{C}$ for $1 \mathrm{~h}$, after that it was left for $24 \mathrm{hrs}$ at room temperature preserving an intermediate stirring.

Distilled water $(230 \mathrm{ml})$ was then added to the mixture, which enforces the temperature to expand to $98{ }^{\circ} \mathrm{C}$ by the effect of the hydration heat. The mixture was kept at this temperature for 30 min under stirring. As a final stage, distilled water $(700 \mathrm{ml})$ and hydrogen peroxide $(30 \%, 300 \mathrm{ml})$ were added. The obtained product had a brown /yellowish color and washed three times with distilled water to remove any remnant ions in the solution. Finally, GO was isolated by vacuum filtration from the solution and later it was dried in oven at $60{ }^{\circ} \mathrm{C}$ for 12 hrs [25]. 


\subsection{Synthesis of magnetite reduced graphene oxide (MRG) composite}

MRGO were prepared by in-situ chemical co-precipitation method. The procedure is as per the following: 1:2 molar ratio of ferrous sulfate $\left(\mathrm{FeSO}_{4}\right)$ and ferric chloride $\left(\mathrm{FeCl}_{3}\right)$ in $80 \mathrm{ml}$ of distilled water under $\mathrm{N}_{2}$ gas. The solution kept under mechanical stirring for $30 \mathrm{~min}$. Then the solution was heated to $70{ }^{\circ} \mathrm{C}$ and kept under stirring for another $30 \mathrm{~min}$. Different amount ratio 10,20 and $30 \mathrm{wt} . \%$ of $\mathrm{GO}$ relative to magnetite was suspended in $50 \mathrm{~mL}$ of distilled water by ultrasonic treatment for 15 min until it turned out to be clear without any observed particles to produced MRG10, MRG20 and MRG30 respectively. GO solutions were added to the mixture of iron solution and the whole mixture was under stirring for another 10 min then ammonia solution (30\%) was added to the mixture until $\mathrm{pH}$ of the mixture is 10 . Moreover of sodium borohydride was added to the solution under mechanical stirring for $10 \mathrm{~min}$ in ordered to make a reduction of GO nanoparticle to obtain reduced graphene oxide .The sample was separated by vacuum filtration from the solution and washed with distilled water and ethanol two times respectively, finally dried in the furnace at $60^{\circ} \mathrm{C}$ for $12 \mathrm{~h} \mathrm{[26].}$

\subsection{Synthesis of $\mathrm{TiO}_{2}$ nanoparticles}

$\mathrm{TiO}_{2}$ nanoparticles were synthesized by hydrolysis method as the following procedure. $7 \mathrm{ml}$ of Titanium (IV) isopropoxide Ti $\left[\mathrm{OCH}\left(\mathrm{CH}_{3}\right)_{2}\right]_{4}$ was dissolved in $100 \mathrm{ml}$ of isopropyl alcohol $\left(\left(\mathrm{CH}_{3}\right)_{2} \mathrm{CHOH}\right)$ and the solution was under stirring for $1 \mathrm{~h}$ at room temperature. After that, $400 \mathrm{ml}$ of distilled water was added abruptly to the mixture. The obtained solution was stirred for another $3 \mathrm{~h}$ at room temperature. The sample was filtrated by vacuum filtration from the solution and washed with distilled water and ethanol three times respectively. The obtained sample was dried at $40^{\circ} \mathrm{C}$ in the oven for $6 \mathrm{hr}$. The synthesis process was then finished by calcinating the precipitated particles at $400^{\circ} \mathrm{C}$ for $2 \mathrm{~h}$ in air [27].

\subsection{Synthesis of $\mathrm{TiO}_{2} / \mathrm{MRG}$ composite}

MRGT composites were prepared with a weight ratio between MRG 20 and $\mathrm{TiO}_{2}$ nanoparticles at (3:1, 1:1 and 1:3) to produced MRGT 25, MRGT 50 and MRGT 75 respectively. Where $\mathrm{TiO}_{2}$ nanoparticles and MRG 20 were suspended each one in $50 \mathrm{ml}$ of ethanol by ultrasonic treatment for 10 min until it turned out to be clear without any observed particles then the two solutions were mixed together by ultrasonic treatment for 10min. After that, the sample was separated by vacuum filtration from the solution and it was put in the oven at $60^{\circ} \mathrm{C}$.

\subsection{Characterization}

The phases of the designed nanomaterials were exanimated via an X-ray diffractometer (XRD, Shimadzu XD-l) with a $\mathrm{Cu}$ Ka radiation at $40 \mathrm{kV}$ and $30 \mathrm{~mA}$ over the 20 range of 4$80^{\circ}$ at a scanning speed of $4 \% / \mathrm{min}$ with a sampling angle interval of $0.04 \circ$. Function groups and bonds are identified using FTIR spectrometer PerkinElmer (model spectrum one FTIR spectrometer, USA). Spectra were recorded between 4000 and $500 \mathrm{~cm}^{-1}$ using standard $\mathrm{KBr}$ pellets. In addition to FTIR, Raman test was carried out using the dispersive Raman microscope (Model Sentera, Bruker, Germany) instrument at laser wave length $532 \mathrm{~nm}$. Morphology and particle size were determined by high resolution transmission electron microscope (TEM-JEOL JEM 2100) and composition was analyzed by Energy dispersive Xray spectroscope (EDX) associated with TEM device. Magnetic measurements were carried out at room temperature using a vibrating sample magnetometer (VSM, 735VSM, Model7410; Lake Shore, Westerville, Ohio, USA) with a maximum magnetic field of $31 \mathrm{kOe}$. UV-VIS/DR spectra were recorded using Jasco V 530 spectrometer (Japan) equipped with the integrating sphere accessory for diffuse reflectance spectra. 


\subsection{Photocatalytic activity}

To check the photocatalytic activity of MRG and MRGT composites, a reaction of TZ solved in water is performed under simulated visible illumination of a halogen lamp (500W). Added catalyst to $50 \mathrm{~mL}$ aqueous $\mathrm{TZ}$ solution $(50 \mathrm{ppm})$ and continuously mechanical stirred for 30 min in dark box, until adsorption-desorption equilibrium is obtained between TZ dye and photocatalyst. The suspension is irradiated as a function of time .Samples are then withdrawn regularly from the reactor and the photocatalyst is separated by an external magnet . The clean transparent solution is analyzed by agilent technologies cary $60 \mathrm{UV}$-vis spectroscopy.

\section{Results and Discussion}

\subsection{Characterization of photocatalysts}

Fig. (1.a) shows the diffraction peaks at $2 \theta$ around 30.27, 35.75, 43.6, 53.73, 57.5, and 63.1, can be listed to the (220), (311), (400), (422), (511) and (440) lattice planes of cubic $\mathrm{Fe}_{3} \mathrm{O}_{4}$ (JCPDS card No. 88-0315), respectively. When the amount of $\mathrm{Fe}_{3} \mathrm{O}_{4}$ diminished, its diffraction peaks in the drawing were -slowly expanded and debilitated, because of little crystal size and more regrettable crystalline of the $\mathrm{Fe}_{3} \mathrm{O}_{4}$ [28]. There might be two explanations behind no peaks from carbon were watched. Firstly, the existence of magnetite decreases the accumulation of graphene sheets, which makes more monolayer graphene prompting to less weak peak from carbon to be watched. Secondly, a strong signal of iron oxides has a tendency to dominate the weak carbon peaks [29].

Crystal structure of MRGTx samples where $\mathrm{x}$ is 25,50 and 75 presnt in Fig. (1.b). The diffraction peaks at $\mathrm{f} 25.3^{\circ}, 37.8^{\circ}, 48^{\circ}, 54^{\circ}, 55.2^{\circ}$ are attributed to (101), (004), (200), (105) and (211) crystallographic planes of anatase phases of $\mathrm{TiO}_{2}$ (JCPDS 21-1272). A (002) diffraction peak at $10.80^{\circ}$ was not seen in $\mathrm{TiO}_{2}-\mathrm{RG}$ composites, which demonstrates that the GO was decreased into RG. The reflection of RG is not seen in the XRD patterns of MRGT composites, perhaps because of the small amount of RG and low intensity of RG. In addition, the distinctive peak of $\mathrm{RG}$ at $24.5^{\circ}$ might be covered by the fundamental peak of anatase $\mathrm{TiO}_{2}$ at 25.3 [30].
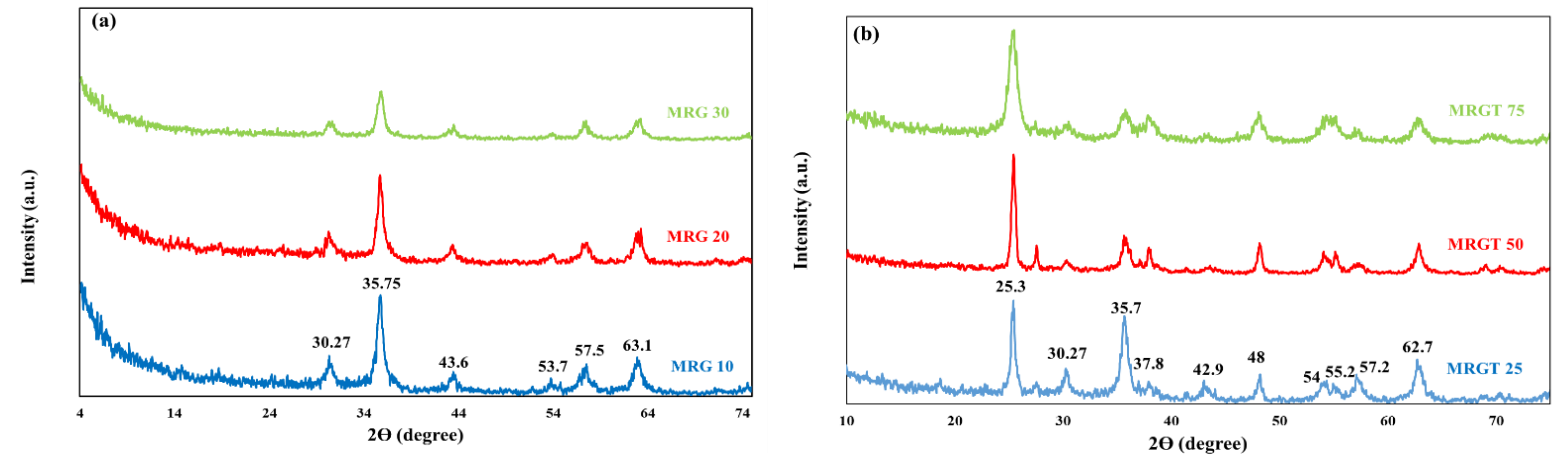

Fig. 1. X-ray diffraction patterns of (a) MRGx and (b) MRGTx samples

In fig (2.a) Raman spectroscopy is a technique that is broadly used to acquire basic data about carbon-based materials. The primary components in the Raman spectra of graphitic carbonbased materials are the $\mathrm{G}$ and $\mathrm{D}$ peaks. The normal features in Raman spectra were the D band situated at $1345 \mathrm{~cm}^{-1}$ and the $G$ band at $1592 \mathrm{~cm}^{-1}$. The $G$ peak match to the optical $E_{2 g}$ phonons at the Brillouin zone center which outcome from the bond stretching of $\mathrm{sp} 2$ carbon 
pairs in both, rings and chains. The D peak demonstrates breathing mode of aromatic rings which grow due to the defect in the sample. The D peak intensity is usually utilized as a measure of the level of disorder. The shift and shape of the overtone of the D peak, called as 2D peak around $2680 \mathrm{~cm}^{-1}$, can be related to the quantity of graphene layers $(\mathrm{N})$ [31].

In Raman spectrum of MRGx (where $\mathrm{x}$ is 10, 20 and 30) there are three peaks situated at 217, $272,367 \mathrm{~cm}^{-1}$, which are related to Fe3O4 nanoparticles as show in Fig (2.b). The wide peaks showed at $1357 \mathrm{~cm}^{-1}$ and $1592 \mathrm{~cm}^{-1}$ are related to the D and $\mathrm{G}$ groups of reduced graphene oxide, respectively [28]. In MRG10, MRG 20 and MRG 30 the two distinctive peaks of G and $\mathrm{D}$ bands still coexist. This means that despite of reduction of GO's band intensity through loading of $\mathrm{Fe}_{3} \mathrm{O}_{4}$, there is no exfoliation between the layers of graphene happened. This affirming that it was a chemical bonding between $\mathrm{Fe}_{3} \mathrm{O}_{4}$ and $\mathrm{GO}$ which coming from replace oxygen in $\mathrm{GO}$ by $\mathrm{Fe}_{3} \mathrm{O}_{4}$ to save exfoliation between the Layers of graphene [32].

Raman spectrum of MRGTx samples presented in Fig (2.c), It display two strong peaks , meant as the disorder peak $\left(\mathrm{D}\right.$, situated at $\left.1357 \mathrm{~cm}^{-1}\right)$ and the graphitic peak ( $\mathrm{G}$, at $\sim 1592 \mathrm{~cm}^{-1}$ ) which are distinctive to reduced graphene oxide finger print.
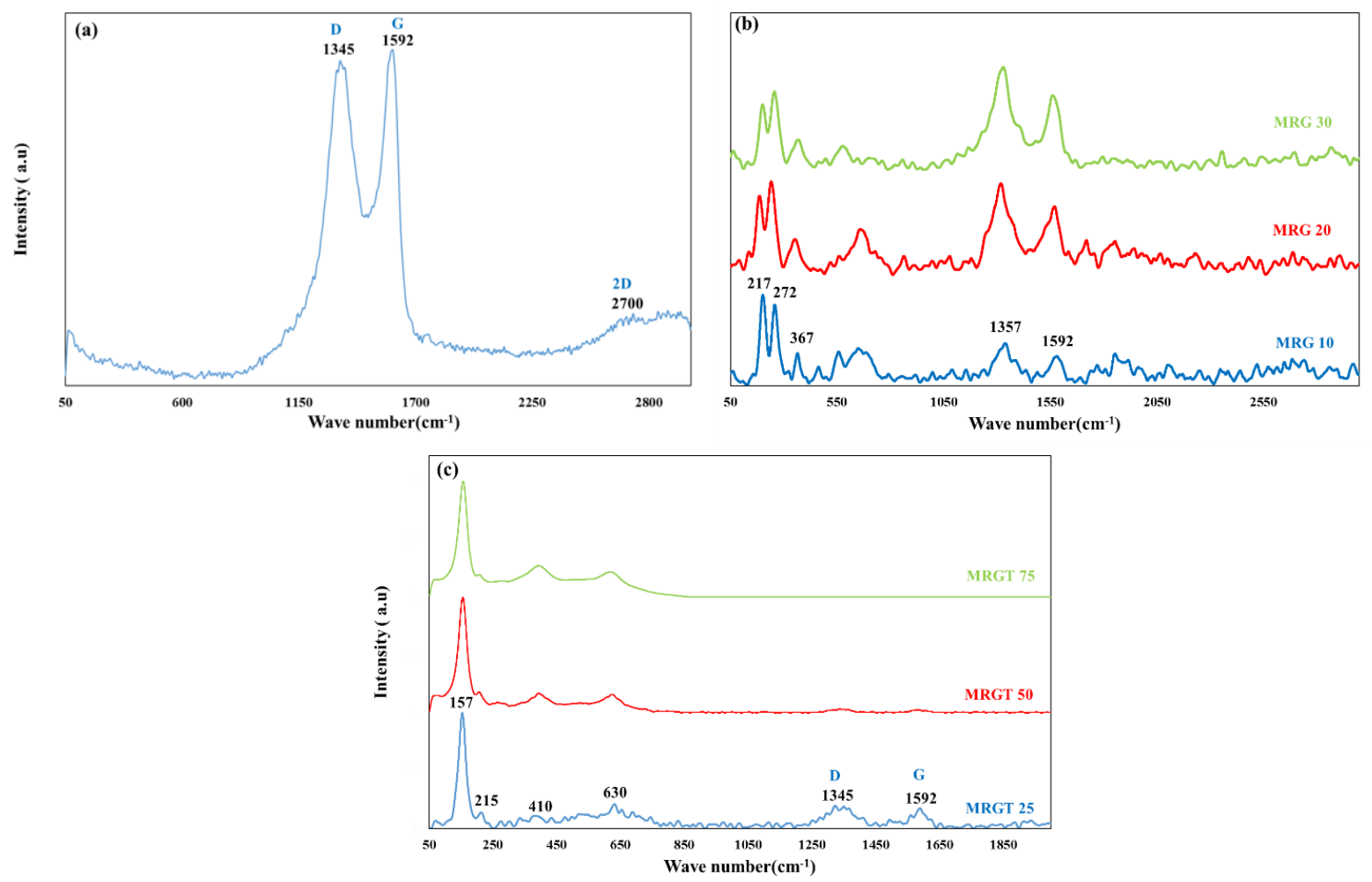

Fig. 2. Raman spectra of all prepared samples

For $\mathrm{TiO}_{2}$, because of $E g$ vibration modes of anatase, a sharp Raman scattering peak for free status anatase nanoparticles is usually seen at $143 \mathrm{~cm}^{-1}$. Conversely, the peak was seen at 157 $\mathrm{cm}^{-1}$. The blue shift from $143 \mathrm{~cm}^{-1}$ to $157 \mathrm{~cm}^{-1}$ might be ascribed to the interaction of RG and $\mathrm{TiO}_{2}$. The peaks at $\sim 215,410,520$ and $630 \mathrm{~cm}^{-1}$ are related to the different vibration modes of anatase [33].

The morphologies of the magnetite with various amounts of reduced graphene oxide $(10 \%$, $20 \%$ and $30 \%$ ) are seen by HRTEM in Fig (3- a, b and c respectively). As indicated the gray part demonstrate the RG nanoparticles, while the dark part demonstrates the aggregates of 
$\mathrm{Fe}_{3} \mathrm{O}_{4}$ nanoparticles[34]. The large amount of $\mathrm{Fe}_{3} \mathrm{O}_{4}$ is kept onto $\mathrm{RG}$ substrates, which shows that some $\mathrm{Fe}^{3+}$ ions could be reduced to $\mathrm{Fe}_{3} \mathrm{O}_{4}$ by in-situ strategy [35]. The magnetite can be distinguished clearly in MRG (10\%and 20\% respectively). Conversely at MRGO 30\% , Graphene tend to cover whole the nanoparticles and hinder activity of these particles[36].

The HRTEM of the MRGT 25, 50 and 75 composites was observed in Fig (3- g, h and i respectively). The $\mathrm{RG}$ sheets were covered with a $\mathrm{TiO}_{2}$ layer, demonstrating loading amount of $\mathrm{TiO}_{2}$, which is combatable with the EDX results. The edge of graphene can be clearly recognized, persuading us the existence of MRG layer under the $\mathrm{TiO}_{2}$ [37].

The EDX spectrum shows $\mathrm{Fe}, \mathrm{O}$ and $\mathrm{C}$ peaks which are related to $\mathrm{MRG}$ composite, (the $\mathrm{O}$ peak coming form $\mathrm{Fe}_{3} \mathrm{O}_{4}$ ). Thus in general there is a good contact between $\mathrm{Fe}_{3} \mathrm{O}_{4}$ nanoparticles and RG [38]. Moreover that gradation of amount Fe refers to well synthesized amount between magnetite and graphene this appear in Fig (3- d, e and f). Also The EDX results for MRGTx composites refer to the existence of $\mathrm{Ti}, \mathrm{Fe}, \mathrm{O}$ and $\mathrm{C}$ elements with prepared percent show in Fig (3- j, k and 1), which confirm the existence of $\mathrm{TiO} 2$ on the surface of MRGO [39].
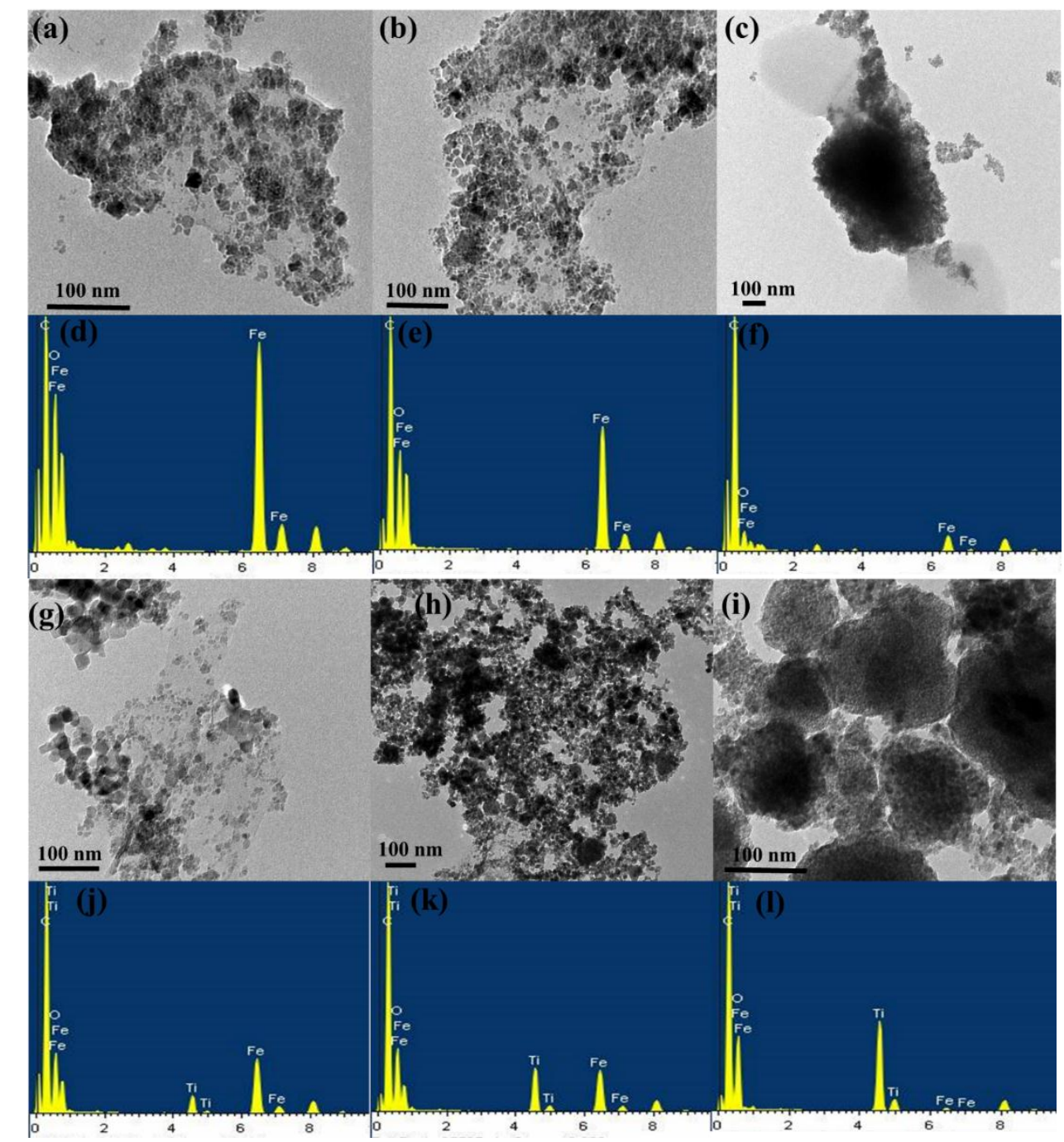

Fig. 3. HRTEM and EDX of (a) and (d) for MRG 10, (b) and (e) for MRG 20, (c) and (f) for MRG 30, (g) and (j) for MRGT 25, (h) and (k) for MRGT 50, (i) and (l) for MRGT 75 
In FT-IR spectra of MRG and MRGT show in Fig ( $4 \mathrm{a}$ and $\mathrm{b}$ ), the broad peak located at about $3400 \mathrm{~cm}^{-1}$ which was assigned to the stretching vibration of O-H. The absorption Peak at 600 $\mathrm{cm}^{-1}$ can be considered as a combination of $\mathrm{Fe}-\mathrm{O}$ vibrations, demonstrating the effective blending of $\mathrm{Fe}_{3} \mathrm{O}_{4}$ nanoparticles and RGO sheets[40]. The absorption band showing up at $1570 \mathrm{~cm}^{-1}$ is related to the skeletal vibration of RGO sheets, which give data about the formation of RGO [41].

The peaks at $1400 \mathrm{~cm}^{-1}$ appear due to the Ti-O-C vibration, which confirm the successful interaction between $\mathrm{Ti}$ and $\mathrm{C}$ and, therefore the impregnation of $\mathrm{TiO} 2$ on reduced graphene oxide (RG) while the absorption band at $584 \mathrm{~cm}^{-1}$ give information about the presence of Ti$\mathrm{O}-\mathrm{Ti}$ bond on the surface of MRGT nanocomposite [42].
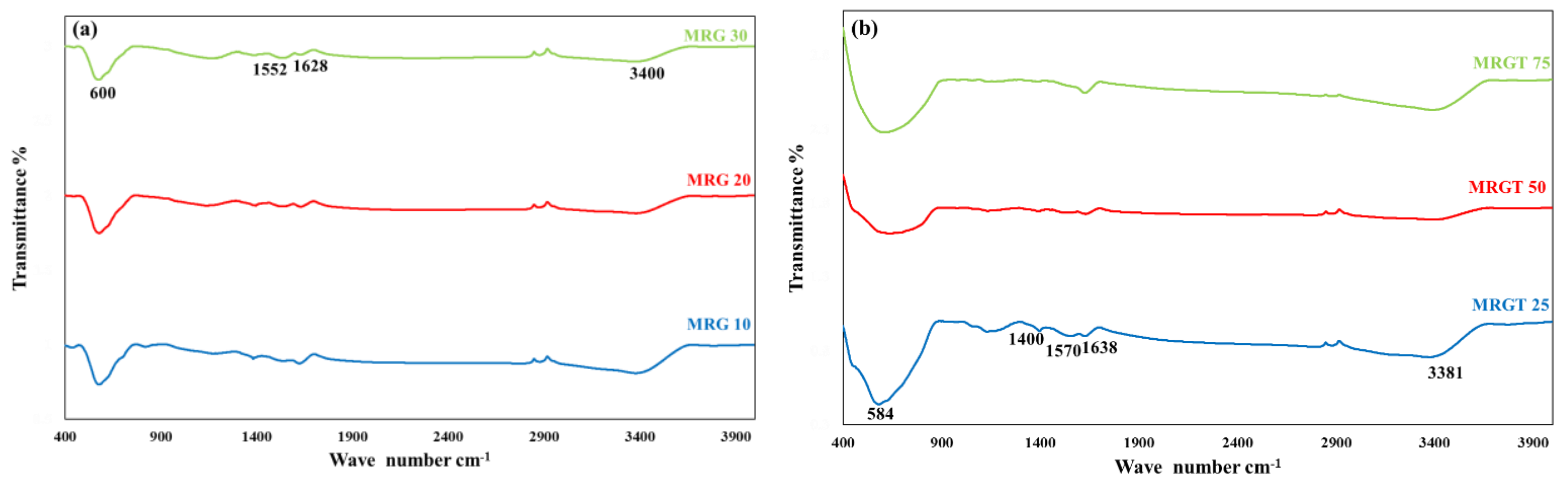

Fig. 4. FT-IR spectra of MRG and MRGT samples

VSM technique was done to know the magnetic behavior of both $\mathrm{Fe}_{3} \mathrm{O}_{4}$ nanopowder and MRG nanocomposite. VSM find the magnetic momentum by vibrating the sample in perpendicular to the regular magnetic field, which is extremely normal and suitable technique for find the magnetic behavior.VSM was done at room temperature and the magnetic behavior results of MRG 10, 20 and 30 are shown in the Fig (5-a). The $\mathrm{Fe}_{3} \mathrm{O}_{4}$ nanoparticles and MRG nanocomposites demonstrate magnetization hysteresis loops and these are S-like curves. All samples of MRG 10, 20 and 30 demonstrated that they have a super paramagnetic behavior with a saturation magnetization of $50,47.3$ and $40.6 \mathrm{emu} / \mathrm{g}$ respectively, which is great for separating nanocomposites from the solution mixture directly and use it again for further uses. $\mathrm{Fe}_{3} \mathrm{O}_{4}$ nanopowder displays ferromagnetic behavior with a saturation magnetization of $51 \mathrm{emu} / \mathrm{g}$, which was observed to be higher than that of MRG nanocomposites. The less value of saturation magnetization in MRG nanocomposites was because of the existence of RG nanosheet in the nanocomposites. [43], [44].

According to the magnetization curves in Fig (5-b), the saturation magnetization of the MRGT (25,75and 75\% proportion) decrease to 34.7, 22.4 and $9.4 \mathrm{emu} / \mathrm{g}$ respectively from 51 $\mathrm{emu} / \mathrm{g}$ in the primary $\mathrm{Fe}_{3} \mathrm{O}_{4}$ sample because of the presence of nonmagnetic materials in the surface of MRG nanocomposite, which is still adequate for rapidly magnetic separation with a suitable magnet field. However, the reversibility in hysteresis loop affirms that no that no aggregation occurs to the nanoparticles in the magnetic fields .[45] 


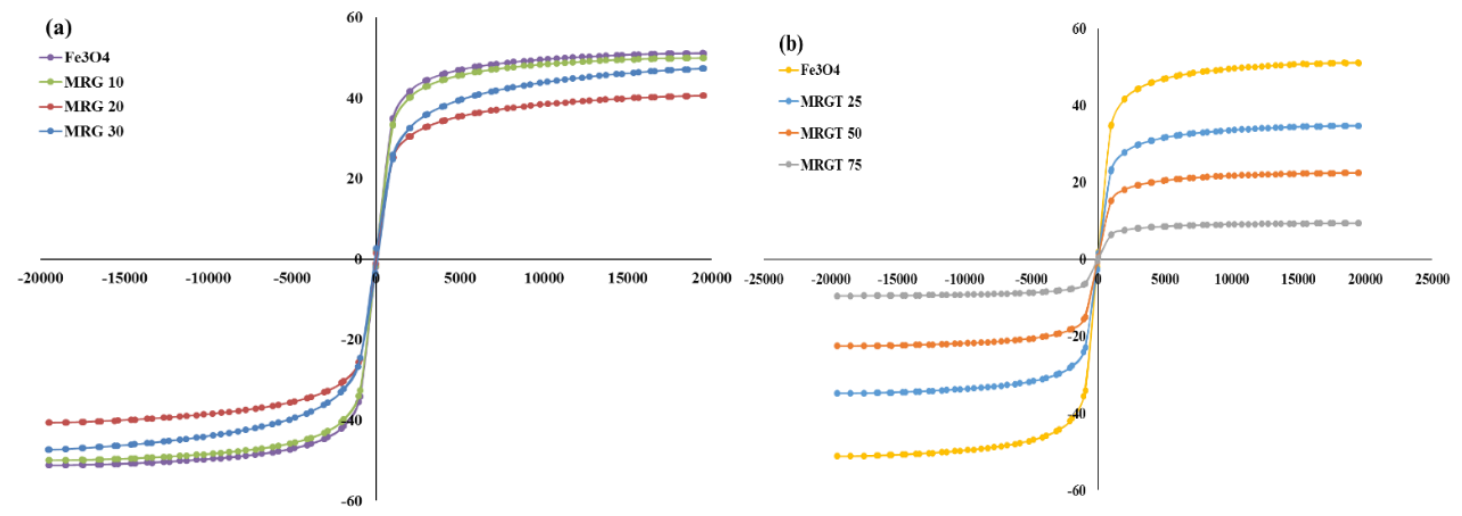

Fig. 5. VSM measurements for magnetic nanoparticles, (a) for MRGx samples and (b) for MRGTx samples.

Fig (6-a) Presents UV-vis diffuse reflectance spectra of MRG 10, 20 and 30 samples. The spectra of sample MRG 20 have a red shift for about $25 \mathrm{~nm}$ relative to MRG 10. This indicates the decrease of the band gap energy. The Eg values were calculated from the $(\mathrm{F}(\mathrm{R}) \mathrm{h} v)^{1 / 2}$ versus hv plots, where $\mathrm{F}(\mathrm{R})=(1-\mathrm{R}) / 2 \mathrm{R}$ (Todorova et. al. 2008). The absorption edges were found to be $598 \mathrm{~nm}$, this value corresponds to the band gap energy of $\mathrm{Eg}=1.8 \mathrm{eV}$ for MRG 20. Then little blue shift for MRG 30, to give the Eg value $1.6 \mathrm{ev}$ as show in Fig (6b) this refers to blocking of magnetite by enriched of reduced graphene layers. So the best ratio of $\mathrm{RGO}$ on $\mathrm{Fe}_{3} \mathrm{O}_{4}$ is $20 \%$ is given smallest $\mathrm{Eg}$ in range semiconductor.
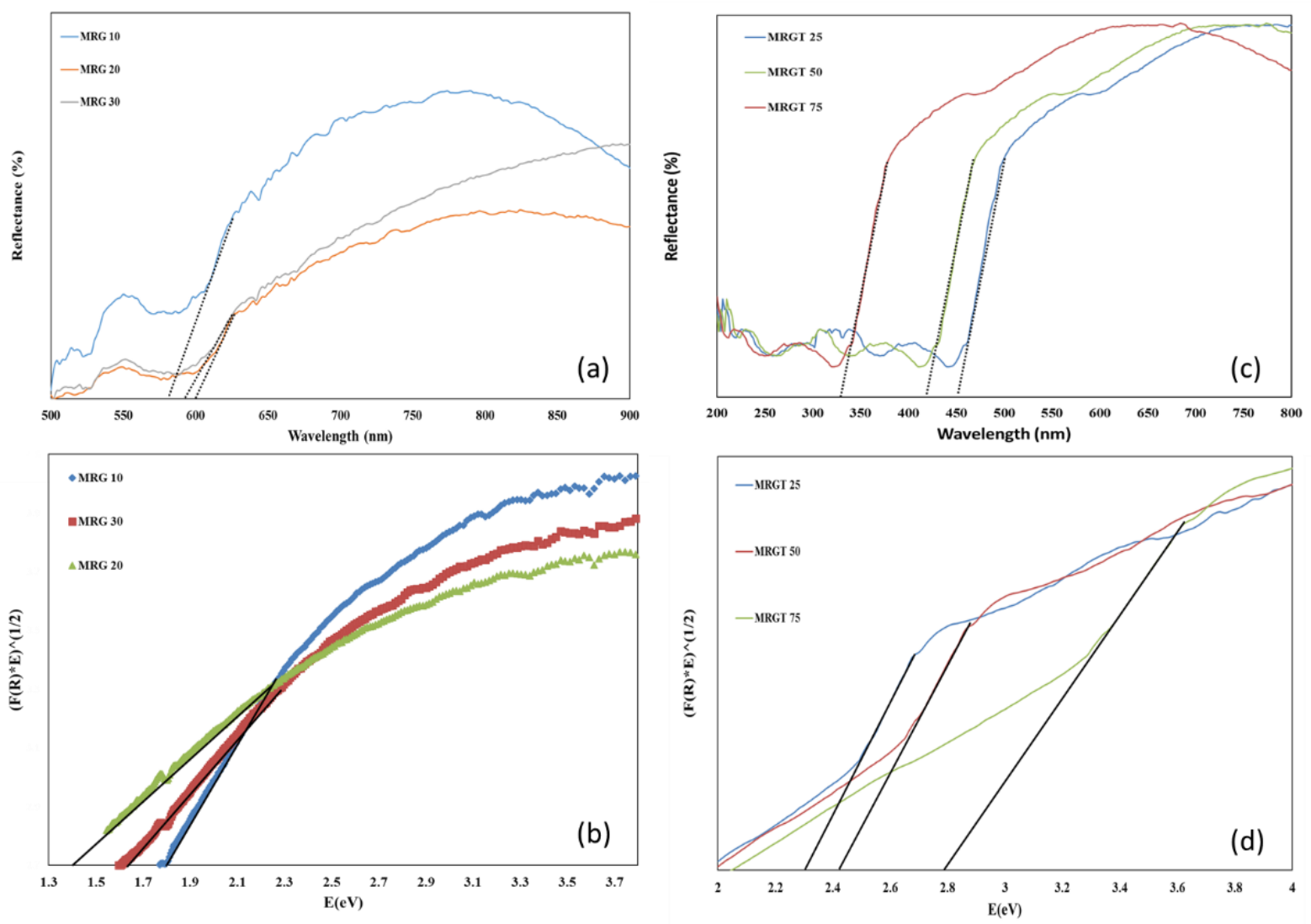

Fig. 6. Diffuse reflectance and $E g$ band gap for all prepared samples 


\subsection{Catalytic activity of MRGx and MRGTx samples}

After added $\mathrm{TiO} 2$ on MRG20 by different ratio presented UV-vis diffuse reflectance spectra in Fig (6-c). From MRGT 25, 50 and 75 given blue shift where at MRGT75 has band gab at $2.8 \mathrm{ev}$ as show in Fig (6-d) and this closely to an ultra violet region. But MRGT 50 has Eg $2.4 \mathrm{ev}$ in the visible region, hence we obtained all benefits of high efficiency from $\mathrm{TiO} 2$ and enhanced in visible region by an optimum ratio of magnetite reduced graphene.

In order to determine the optimal photocatalyst of MRG (either MRG10, 20 or 30) to used it as a substrate to loading $\mathrm{TiO}_{2}$ nanoparticle on its surface, an experiment was performed at room temperature by varying the time from 0 to $210 \mathrm{~min}$.The effect of time on the rate of degradation indicates that optimum catalyst loading was MRG 20 as shown in Fig (7). The rate of degradation increases with increase the amount of loading graphene on the surface of magnetite from MRG10 to MRG 20. In MRG 30 we observed that the rate of degradation is decreased, This is probably due to increasing in the amount of loading graphene (RG) on magnetite surface is lead to the complete cover of nanoparticles and hinder the photocatalytic activity of this particles this matched with data from band gap and HR-TEM.

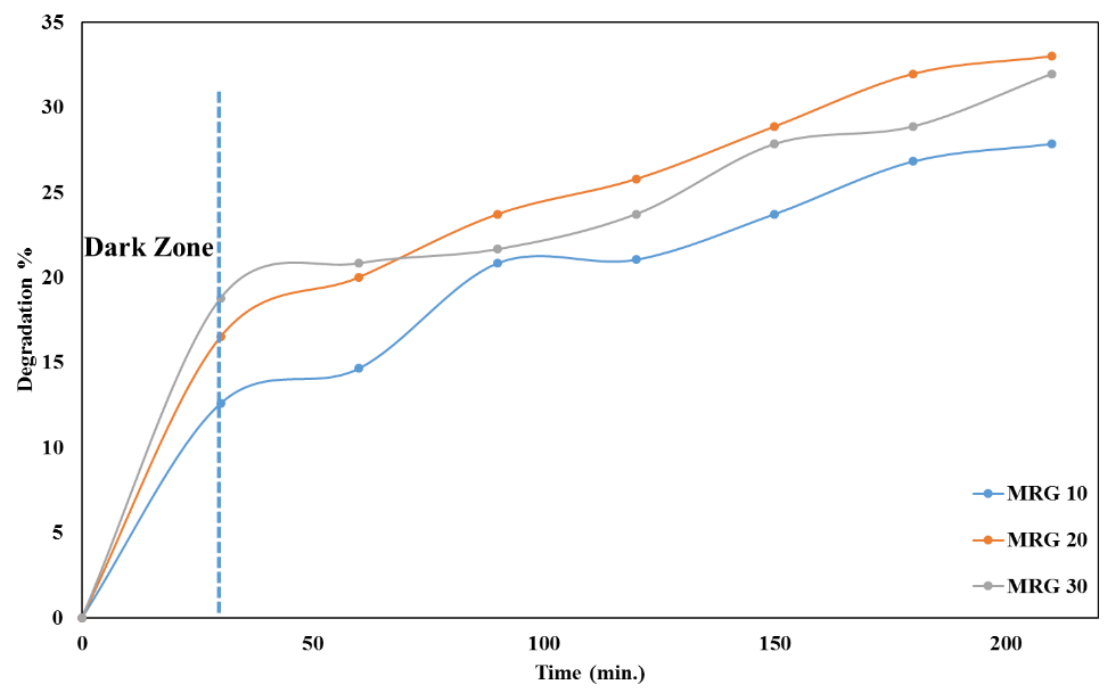

Fig. 7. Photocatalytic degradation of tartrazine by MRGx samples

Study of TZ degradation by MRGT 25, 50 and 75, an experiment was performed at room temperature by varying the time from 0 to $210 \mathrm{~min}$.The effect of time on the rate of degradation indicates that the optimum catalyst loading on MRG 20 is MRGT 50 as shown in Fig (8). The rate of degradation increases with increase the amount of loading $\mathrm{TiO}_{2}$ on the surface of MRG 20 from MRGT 25 to MRGT 50. In MRGT 75 we observed that the rate of degradation is decreased, This is probably due to increasing in the amount of loading $\mathrm{TiO}_{2}(\mathrm{~T})$ on MRG 20 surface where the excess of titanium dioxide have shifted the composite to work in UV region not in the visible region, so give less activity. And by comparing with $\mathrm{TiO}_{2}$ which give activity less than $10 \%$ of degradation this refer to not working of $\mathrm{TiO}_{2}$ in visible light and also strong TZ day to degradation by it only. 


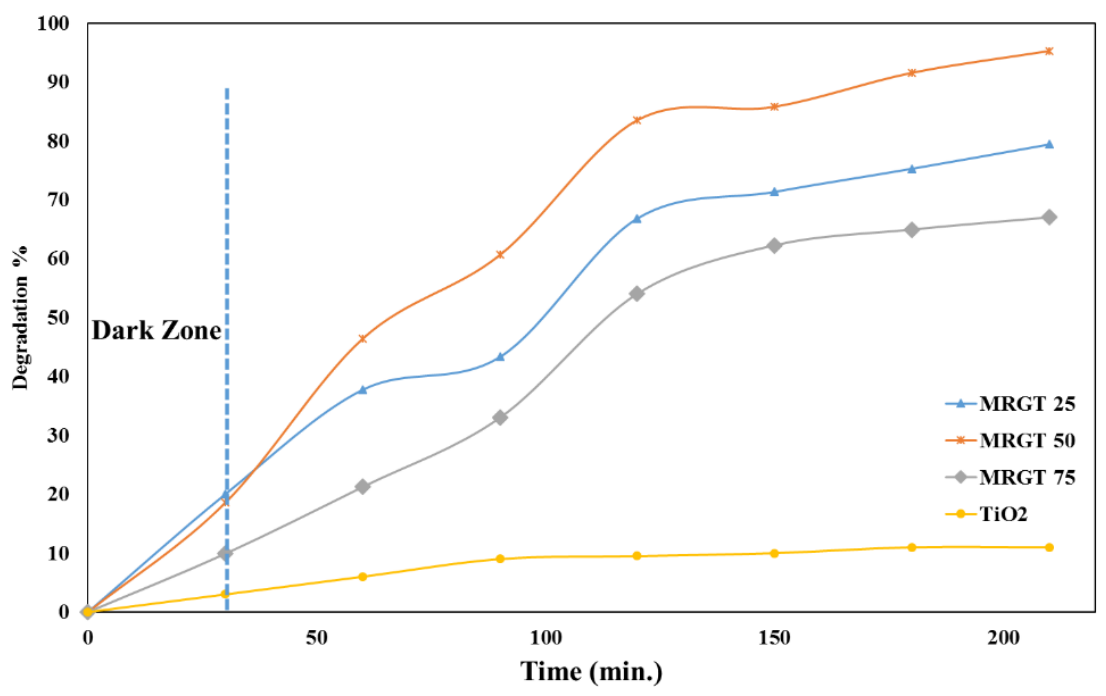

Fig. 8. Photocatalytic degradation of TZ by MRGT25, 50, 75 and TiO2 samples

\subsection{MRGT50 effective conc. and its endurance against high concentrations}

To determine the optimal amount of the MRGT50 sample. The experiments are performed at room temperature by varying the amount of catalyst from 0.15 to $0.3 \mathrm{~g} / \mathrm{l}$. The effect of MRGT 50 loadings on the rate of degradation indicates that optimum catalyst concentration is $0.2 \mathrm{~g} / \mathrm{l}$ show in Fig (9-a). The rate increases with increase in catalyst concentration from 0.15 to $0.2 \mathrm{~g} / \mathrm{l}$. This is probably due to increasing in the amount of photocatalyst, which increases the number of photons and dye molecules absorbed. The increase of the catalyst concentration to more than $0.2 \mathrm{~g} / \mathrm{l}$ results in the decrease of degradation rate. This phenomenon may be explained by aggregation of MRGT 50 at high concentrations. It causes a decrease in the number of surface active sites, which increases the opacity and lights scattering of MRGT 50, leading to a decrease in the passage of irradiation through the sample.

Experiments are performed at a different concentration of TZ 50, 100 and 200 ppm, against MRGT 50 [0.2g/l], at room temperature .Degradation rate appears to decrease with increasing TZ concentration in Fig (9-b). This is because active sites of the photocatalyst are occupied by $\mathrm{TZ}$ molecules and fewer photons can reach the surface of the catalyst .Therefore, the possibility of photocatalyst excitation is diminished. At higher concentration levels, the screening effect also dominates and hence, degradation efficiency decreases.

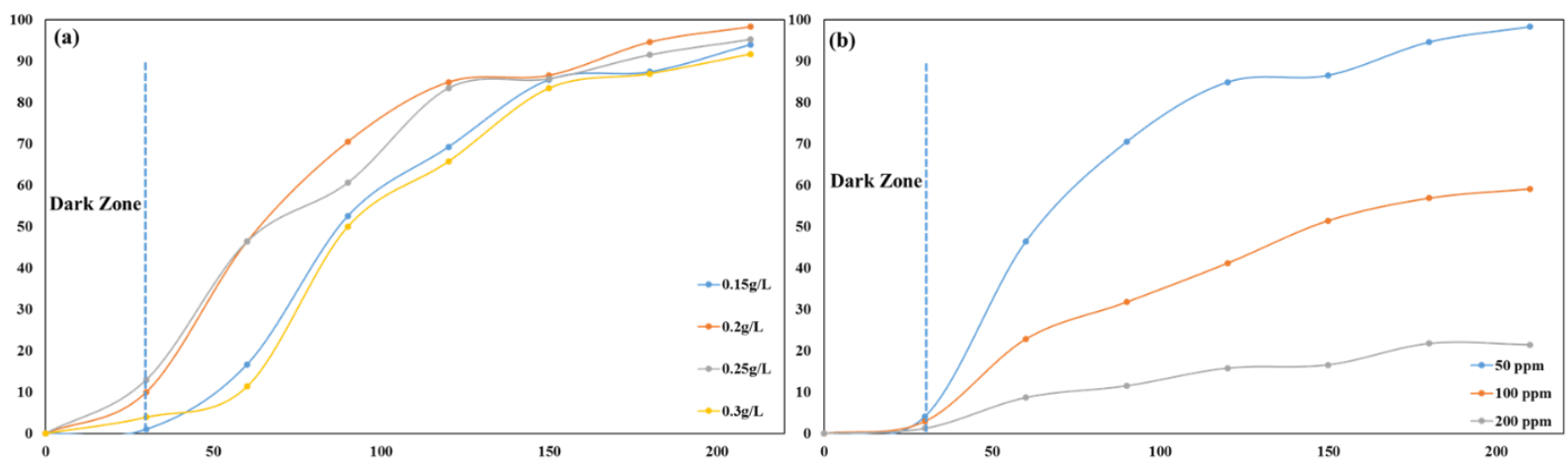

Fig. 9. (a) Effect of weight catalyst MRGT50 (b) Effect of TZ concentration 


\section{Conclusion}

A magnetically separable MRG and MRGT photocatalyst has been successfully prepared. TEM observations indicate that graphene sheets are fully exfoliated and decorated with $\mathrm{Fe}_{3} \mathrm{O}_{4}$ and $\mathrm{TiO} 2$ nanoparticles . The photocatalytic activity measurements show coupling $\mathrm{Fe}_{3} \mathrm{O}_{4}$ and TiO2 nanoparticles with graphene sheets which lead to high photocatalytic activity in degradation of $\mathrm{TZ}$ under visible light irradiation reach to more than $95 \%$ degradation of pollutant .In contrast, $\mathrm{TiO}_{2}$ alone is almost inactive in our experimental condition. Easley separation of photocatalyst by a magnet to prevent secondary pollution.

\section{References}

[1] R. Saravanan, S. Karthikeyan, V. Gupta, G. Sekaran, V. Narayanan, and A. Stephen, "Enhanced photocatalytic activity of $\mathrm{ZnO} / \mathrm{CuO}$ nanocomposite for the degradation of textile dye on visible light illumination," Materials Science and Engineering: $C$, vol. 33, pp. 91-98, 2013.

[2] T. T. Hameed, B. M. Fahad, and N. S. Ali, "USING LOW COST WASTE GLASS ADSORBENT FOR METHYL VIOLET REMOVAL FROM WASTE WATER," 2017.

[3] S. Papić, N. Koprivanac, A. L. Božić, and A. Meteš, "Removal of some reactive dyes from synthetic wastewater by combined $\mathrm{Al}$ (III) coagulation/carbon adsorption process," Dyes and Pigments, vol. 62, pp. 291-298, 2004.

[4] A. Mittal, L. Kurup, and J. Mittal, "Freundlich and Langmuir adsorption isotherms and kinetics for the removal of Tartrazine from aqueous solutions using hen feathers," Journal of hazardous materials, vol. 146, pp. 243-248, 2007.

[5] I. G. Bacioiu, L. Stoica, C. Constantin, and A. M. Stanescu, "Adsorption Equilibrium and Kinetics Modeling for Tartrazine (E102)-Fe (II) Based Adsorbent System," REVISTA DE CHIMIE, vol. 67, pp. 2391-2395, 2016.

[6] A. Weisz, C. D. Ridge, J. A. Roque, E. P. Mazzola, and Y. Ito, "Preparative separation of two subsidiary colors of FD\&C Yellow No. 5 (Tartrazine) using spiral high-speed counter-current chromatography," Journal of Chromatography A, vol. 1343, pp. 91100, 2014.

[7] Z. Atlı Şekeroğlu, B. Güneş, S. Kontaş Yedier, V. Şekeroğlu, and B. Aydın, "Effects of tartrazine on proliferation and genetic damage in human lymphocytes," Toxicology Mechanisms and Methods, pp. 1-17, 2017.

[8] A. Rafati, N. Nourzei, S. Karbalay-Doust, and A. Noorafshan, "Using vitamin E to prevent the impairment in behavioral test, cell loss and dendrite changes in medial prefrontal cortex induced by tartrazine in rats," Acta histochemica, vol. 119, pp. 172180, 2017.

[9] M. A. Habila, Z. A. ALOthman, R. Ali, A. A. Ghafar, and M. S. E. D. Hassouna, "Removal of Tartrazine Dye onto Mixed-Waste Activated Carbon: Kinetic and Thermodynamic Studies," CLEAN-Soil, Air, Water, vol. 42, pp. 1824-1831, 2014.

[10] G. El-Desoky, A. Abdel-Ghaffar, Z. Al-Othman, M. Habila, Y. Al-Sheikh, H. Ghneim, et al., "Curcumin protects against tartrazine-mediated oxidative stress and hepatotoxicity in male rats," European Review for Medical and Pharmacological Sciences, vol. 21, pp. 635-645, 2017.

[11] N. Arabzadeh, A. Khosravi, A. Mohammadi, and N. M. Mahmoodi, "Enhanced photodegradation of hazardous tartrazine by composite of nanomolecularly imprinted polymer-nanophotocatalyst with high efficiency," Desalination and Water Treatment, vol. 57, pp. 3142-3151, 2016. 
[12] L. Rizzo, H. Selcuk, A. Nikolaou, S. Meriç Pagano, and V. Belgiorno, "A comparative evaluation of ozonation and heterogeneous photocatalytic oxidation processes for reuse of secondary treated urban wastewater," Desalination and Water Treatment, vol. 52, pp. 1414-1421, 2014.

[13] C. Sichel, J. Blanco, S. Malato, and P. Fernandez-Ibanez, "Effects of experimental conditions on E. coli survival during solar photocatalytic water disinfection," Journal of Photochemistry and photobiology A: Chemistry, vol. 189, pp. 239-246, 2007.

[14] S. Naama, T. Hadjersi, H. Menari, G. Nezzal, L. B. Ahmed, and S. Lamrani, "Enhancement of the tartrazine photodegradation by modification of silicon nanowires with metal nanoparticles," Materials Research Bulletin, vol. 76, pp. 317-326, 2016.

[15] Y. Wu, Y. Zhou, Y. Liu, Y. Wang, L. Yang, and C. Li, "Photocatalytic performances and characterizations of sea urchin-like N, Ce codoped TiO2 photocatalyst," Materials Research Innovations, vol. 21, pp. 33-39, 2017.

[16] S. Ghasemi, S. Hashemian, A. Alamolhoda, I. Gocheva, and S. R. Setayesh, "Plasmon enhanced photocatalytic activity of Au@ TiO 2-graphene nanocomposite under visible light for degradation of pollutants," Materials Research Bulletin, vol. 87, pp. 40-47, 2017.

[17] M. Nasr, S. Balme, C. Eid, R. Habchi, P. Miele, and M. Bechelany, "Enhanced Visible-Light Photocatalytic Performance of Electrospun $\mathrm{rGO} / \mathrm{TiO} 2$ Composite Nanofibers," The Journal of Physical Chemistry C, 2016.

[18] B. Bhanvase, T. Shende, and S. Sonawane, "A review on graphene-TiO2 and doped graphene-TiO2 nanocomposite photocatalyst for water and wastewater treatment," Environmental Technology Reviews, vol. 6, pp. 1-14, 2017.

[19] C. K. Chua and M. Pumera, "Chemical reduction of graphene oxide: a synthetic chemistry viewpoint," Chemical Society Reviews, vol. 43, pp. 291-312, 2014.

[20] Y. Fan, X. Yang, C. Yang, and J. Liu, "Au-TiO2/Graphene Nanocomposite Film for Electrochemical Sensing of Hydrogen Peroxide and NADH," Electroanalysis, vol. 24, pp. 1334-1339, 2012.

[21] X. Xie, J. Long, J. Xu, L. Chen, Y. Wang, Z. Zhang, et al., "Nitrogen-doped graphene stabilized gold nanoparticles for aerobic selective oxidation of benzylic alcohols," RSC Advances, vol. 2, pp. 12438-12446, 2012.

[22] J.-J. Zhang, X. Liu, T. Ye, G.-P. Zheng, X.-C. Zheng, P. Liu, et al., "Novel assembly of homogeneous reduced graphene oxide-doped mesoporous TiO 2 hybrids for elimination of Rhodamine-B dye under visible light irradiation," Journal of Alloys and Compounds, vol. 698, pp. 819-827, 2017.

[23] H. Zhang, X. He, W. Zhao, Y. Peng, D. Sun, H. Li, et al., "Preparation of Fe3O4/TiO2 magnetic mesoporous composites for photocatalytic degradation of organic pollutants," Water Science and Technology, p. wst2017002, 2017.

[24] Z.-Q. Li, H.-L. Wang, L.-Y. Zi, J.-J. Zhang, and Y.-S. Zhang, "Preparation and photocatalytic performance of magnetic TiO 2-Fe 3 O 4/graphene (RGO) composites under VIS-light irradiation," Ceramics International, vol. 41, pp. 10634-10643, 2015.

[25] J. Guerrero-Contreras and F. Caballero-Briones, "Graphene oxide powders with different oxidation degree, prepared by synthesis variations of the Hummers method," Materials Chemistry and Physics, vol. 153, pp. 209-220, 2015.

[26] P. Wang, X. Zhou, Y. Zhang, L. Wang, K. Zhi, and Y. Jiang, "Synthesis and application of magnetic reduced graphene oxide composites for the removal of bisphenol A in aqueous solution - a mechanistic study," RSC Advances, vol. 6, pp. 102348-102358, 2016.

[27] S. Kanmani and K. Ramachandran, "Synthesis and characterization of $\mathrm{TiO} 2 / \mathrm{ZnO}$ core/shell nanomaterials for solar cell applications," Renewable Energy, vol. 43, pp. 149-156, 2012. 
[28] J. Cheng, Q. Shou, J. Wu, F. Liu, V. P. Dravid, and X. Zhang, "Influence of component content on the capacitance of magnetite/reduced graphene oxide composite," Journal of Electroanalytical Chemistry, vol. 698, pp. 1-8, 2013.

[29] X. Yang, C. Chen, J. Li, G. Zhao, X. Ren, and X. Wang, "Graphene oxide-iron oxide and reduced graphene oxide-iron oxide hybrid materials for the removal of organic and inorganic pollutants," RSC Advances, vol. 2, pp. 8821-8826, 2012.

[30] L. Liu, C. Luo, J. Xiong, Z. Yang, Y. Zhang, Y. Cai, et al., "Reduced graphene oxide (rGO) decorated $\mathrm{TiO} 2$ microspheres for visible-light photocatalytic reduction of $\mathrm{Cr}$ (VI)," Journal of Alloys and Compounds, vol. 690, pp. 771-776, 2017.

[31] L. Shahriary and A. A. Athawale, "Graphene oxide synthesized by using modified hummers approach," Int J Renew Energy Environ Eng, vol. 2, pp. 58-63, 2014.

[32] H. H. El-Maghrabi, S. M. Abdelmaged, A. A. Nada, F. Zahran, S. A. El-Wahab, D. Yahea, et al., "Magnetic graphene based nanocomposite for uranium scavenging," Journal of Hazardous Materials, vol. 322, pp. 370-379, 2017.

[33] J. Qiu, P. Zhang, M. Ling, S. Li, P. Liu, H. Zhao, et al., "Photocatalytic synthesis of $\mathrm{TiO} 2$ and reduced graphene oxide nanocomposite for lithium ion battery," ACS applied materials \& interfaces, vol. 4, pp. 3636-3642, 2012.

[34] C. H. Hong, M. W. Kim, W. L. Zhang, I. J. Moon, and H. J. Choi, "Fabrication of smart magnetite/reduced graphene oxide composite nanoparticles and their magnetic stimuli-response," Journal of Colloid and Interface Science, vol. 481, pp. 194-200, 2016.

[35] Y. Wang, Q. Liu, Q. Qi, J. Ding, X. Gao, Y. Zhang, et al., "Electrocatalytic oxidation and detection of $\mathrm{N}$-acetylcysteine based on magnetite/reduced graphene oxide composite-modified glassy carbon electrode," Electrochimica Acta, vol. 111, pp. 3140, 2013.

[36] H. H. El-Maghrabi, E. A. Nada, F. S. Soliman, Y. M. Moustafa, and A. E.-S. Amin, "One pot environmental friendly nanocomposite synthesis of novel TiO 2-nanotubes on graphene sheets as effective photocatalyst," Egyptian Journal of Petroleum, 2016.

[37] M. Shi, J. Shen, H. Ma, Z. Li, X. Lu, N. Li, et al., "Preparation of graphene-TiO 2 composite by hydrothermal method from peroxotitanium acid and its photocatalytic properties," Colloids and Surfaces A: Physicochemical and Engineering Aspects, vol. 405, pp. 30-37, 2012.

[38] S. Morales-Torres, L. M. Pastrana-Martínez, J. L. Figueiredo, J. L. Faria, and A. M. Silva, "Graphene oxide-P25 photocatalysts for degradation of diphenhydramine pharmaceutical and methyl orange dye," Applied Surface Science, vol. 275, pp. 361368, 2013.

[39] M. Ghavami, R. Mohammadi, M. Koohi, and M. Kassaee, "Visible light photocatalytic activity of reduced graphene oxide synergistically enhanced by successive inclusion of $\gamma$-Fe $2 \mathrm{O} 3$, TiO 2, and Ag nanoparticles," Materials Science in Semiconductor Processing, vol. 26, pp. 69-78, 2014.

[40] Y. Gao, D. Zhong, D. Zhang, X. Pu, X. Shao, C. Su, et al., "Thermal regeneration of recyclable reduced graphene oxide/Fe3O4 composites with improved adsorption properties," Journal of Chemical Technology and Biotechnology, vol. 89, pp. 1859$1865,2014$.

[41] M. S. A. Sher Shah, A. R. Park, K. Zhang, J. H. Park, and P. J. Yoo, "Green synthesis of biphasic TiO2-reduced graphene oxide nanocomposites with highly enhanced photocatalytic activity," ACS applied materials \& interfaces, vol. 4, pp. 3893-3901, 2012.

[42] P. Benjwal, M. Kumar, P. Chamoli, and K. K. Kar, "Enhanced photocatalytic degradation of methylene blue and adsorption of arsenic (iii) by reduced graphene oxide (rGO)-metal oxide ( $\mathrm{TiO} 2 / \mathrm{Fe} 3 \mathrm{O} 4$ ) based nanocomposites," Rsc Advances, vol. 5, pp. 73249-73260, 2015. 
[43] P. K. Boruah, D. J. Borah, J. Handique, P. Sharma, P. Sengupta, and M. R. Das, "Facile synthesis and characterization of Fe $3 \mathrm{O} 4$ nanopowder and Fe $3 \mathrm{O}$ 4/reduced graphene oxide nanocomposite for methyl blue adsorption: A comparative study," Journal of Environmental Chemical Engineering, vol. 3, pp. 1974-1985, 2015.

[44] F. Deng, X. Lu, X. Pei, X. Luo, S. Luo, and D. D. Dionysiou, "Fabrication of ternary reduced graphene oxide/SnS 2/ZnFe 2 O 4 composite for high visible-light photocatalytic activity and stability," Journal of Hazardous Materials, 2017.

[45] E. Tabrizian and A. Amoozadeh, "A unique approach to magnetization of metal oxides: nano-Fe 3 O 4@ TDI@ TiO 2 as a highly efficient, magnetically separable and recyclable heterogeneous nanocatalyst," Catalysis Science \& Technology, vol. 6, pp. 6267-6276, 2016. 